\title{
The Application of PAD Class in the Basic English Course at Anshan Normal University under the Theory of Second Language Acquisition
}

\author{
Dan Guo \\ School of Foreign Languages \\ Anshan Normal University \\ Anshan, China \\ Email: guodanxuri@126.com
}

\begin{abstract}
Second language acquisition means that people learn a language other than their mother tongue in a certain way. PDA Class is a new teaching method, which emphasizes the internalization of knowledge by learners and emphasizes the process evaluation of learning outcomes. The effective learning strategies are combined and complemented with the PDA Class teaching modes, which are actively applied in the basic English classroom at Anshan University in order to maximize students' interest in learning and improve the teaching quality.
\end{abstract}

Keywords-Second language acquisition; PDA class; Learning strategy; Teaching method

\section{INTRODUCTION}

The second language refers to another or two or even more languages in which the learner re-learns in or outside the classroom after learning the mother tongue. The study of L2 learning strategies has received widespread attention in recent years and has achieved some breakthrough results. Aiming at the main problems existing in current college classrooms, combined with the advantages of lecture-style classrooms and discussion-type classrooms, a new classroom teaching reform model named "PDA Class" was proposed. The core idea is to allocate half the class time to the teacher, the other half to the students to discuss, and to stagger the teaching and discussion time, so that students have a week of self-study after class to conduct learning, personalized internal absorption. The corresponding assessment method emphasizes process evaluation and focuses on different learning needs. Pilot teaching shows that PAD Class effectively enhances students' initiative in learning and teaching results are good. The PDA Class may be a kind of college teaching model suitable for China's national conditions, and it is worth further experimentation and promotion.

\section{PROBLEMS IN COLLEGE TEACHING MODELS}

In recent years, the rapid development of higher education in China has transformed from elite education to mass education. However, there has been a significant reduction in the quality of education. Classroom absenteeism in colleges and universities is high, students play mobile phones, chat, and stay in a daze. It is quite common for the students to be indifferent or not to learn from the teaching content. Zhang Dejiang summed up this phenomenon as three problems: "Learning without practice, knowing without knowledge, digesting without textualization." [1] which reflects the student's non-prepared and non-reviewed learning style and state issues; students accept knowledge passively, without really transforming and absorbing it; knowledge cannot be internalized as a matter of spirit and quality.

Although colleges and universities have a variety of hightech teaching tools, rich teaching resources, and advanced teaching concepts, most of the theoretical teaching models are still based on traditional teaching methods. That is, many years of exam-oriented education and full classroom irrigation and spoon-feeding teaching methods. There are five "too many and too few" problems in the teaching methods of teachers: too much infuse, too little participation; too many conclusions and too few problems; too much closed type, too little divergence; too many heavy points and too little weight; too much knowledge of books, too little knowledge of practice and problem solving skills [2]. If teaching makes students' interest and passion for learning impaired, they are only used to passive acceptance and memorization. Without independent thinking and positive thinking, what kind of "talent" will be cultivated in higher education? 


\section{THE GUIDING ROLE OF SECOND LANGUAGE ACQUISITION THEORY IN FOREIGN LANGUAGE TEACHING}

In recent years, the second language acquisition research has achieved rapid development. This area focuses on the characteristics of learners and their role in the acquisition process, focusing on two major issues: the first is to explore the common characteristics to learners in the learning process; the second is to explore the individual differences in learners. The foreign language teaching in China must proceed from the specific conditions of Chinese foreign language teaching and establish its own foreign language teaching theory system. We should take a cautious attitude toward foreign language teaching theory, and we should fully consider the special circumstances of Chinese students learning foreign languages in the process of absorbing and drawing lessons. This is particularly true of the second language acquisition theory's active instructional role in foreign language teaching in China, especially English teaching in universities. The second language acquisition theory's guiding role in college English teaching can be reflected in: enable students to gain more and more opportunities to use the target language directly; students are immersed in the use of the target language environment for meaningful communication and can inspire students to participate in problem-solving and task-communicating activities. In other words, this kind of foreign language classroom teaching environment conducive to students' acquisition of language should have the following characteristics: natural and content-oriented, students can participate directly in communication. The content should be concrete and not too abstract. We must provide various models for students to imitate.

\section{IV. "SECOND LANGUAGE ACQUISITION +PAD Class" ENGLISH MAJOR TEACHING MODEL}

Second language acquisition provides an emotional basis for English learning. In general, learners do not absorb the language materials they come into contact with. When they choose to study materials, they filter the materials according to their own interests, hobbies, needs, or the depth of materials [3]. Therefore, the input language of English learners must be attractive and satisfy the needs and tastes of English learners.

Second language acquisition provides a greater classroom atmosphere for English learning. First of all, one of the biggest difficulties for Chinese in learning English is the serious lack of a target language environment. Therefore, it is very important to maximize student contact in the classroom and improve the language environment for English learning so that each student can naturally acquire the language in a natural, authentic and meaningful communication process. Second, the input of corpus provided in class cannot be compared with the real language environment, which can provide more, more time-sensitive and authentic language input. Furthermore, the English lesson itself makes students realize that they are learning a foreign language, which will result in strong emotional filtering and affect the learning effect [4]. Therefore, no matter how colorful language activities are designed, the classroom is always an artificial language environment, providing as much as possible a real language world.
Second language acquisition provides a theoretical basis for teaching research in English learning. For a long period of time in the past, the focus of English language teaching research was mainly on "how to teach" and tried to solve the problem of language learning through teaching and research. The birth of cognitive psychology and transformational generative linguistics has led to a shift in the understanding of English learning among English teachers and researchers. The focus of English research has also begun to shift from "how to teach" to "how to learn" [5]. This happens to coincide with the core concept of the class-division classroom.

Language learning requires a lot of practice. The key idea of the PAD Class is to allocate half of the class time to teacher's presentation and the other half to students' discussion. These different forms of discussion increase the length and frequency of students' actual practice of English language, which can effectively help students use the knowledge they have learned, thus realizing the innovative ability-training model centered on students, problems, and activities. In addition, in the assessment method, emphasis is placed on classifying classroom assessments and focusing on different learning needs so that students can determine their investment in the curriculum based on their individual learning goals. The PAD Class teaching process is divided into three processes that are clearly separated in time, they are Presentation, Assimilation and Discussion [6].

Based on the above understanding, this study proposes a teaching model combining the study of second language acquisition and the PAD Class, and takes the advantages of the two to complement each other. By establishing a practice model of "professional class teaching and class discussion", supplemented by "effective autonomous learning and assessment", to make up for and expand the deficiency of the current college English teaching model, and to better improve students' ability to use English language comprehensively, so as to improve the professional English teaching effect.

\section{CHARACTERISTICS OF "SECOND LANGUAGE ACQUISITION +PAD CLASS" COLLEGE ENGLISH TEACHING MODEL}

Rich auxiliary teaching resources under effective learning strategies. First of all, the rich teaching resources break the limitation that teachers are the only source of information in the classroom, enrich and expand the classroom learning, and students can "self-study" according to their actual situation "anytime, anywhere". The high-quality multimedia resources restore the real scenes of English language use, and can promote students to "be in the environment" to feel and imitate the use of authentic language to express their own ideas. Second, students can learn different content according to their own advantages and disadvantages, such as listening skills, communication strategies, writing skills, reading strategies, and translation skills. In this way, it is possible to provide students with a good foundation in language with conditions for further deepening and improving language knowledge and skills, and to review and supplement classes for students with poor language foundation. 
Redistribution of class time. In the "second language acquisition+PAD Class" teaching model, the teacher only spends half of the class time to explain the difficulty of the textbook, and the other half is left for students to learn interactively. The teacher converts the original knowledge into the promoter of the learning. , mentors and planners for learning activities. At the same time, the reduction in teaching time will reduce the requirement for students to pay attention to classes. Students will pay more attention to the transfer of teachers' core knowledge and the efficiency of classroom learning will be higher. By reducing the time for teachers to explain and increase the length of students' actual language drills, coupled with the "assimilation" of students' knowledge gained after class, students are "ready to come" in class discussions, and accuracy, fluency and validity of language expressions will be increased.

Changes in student roles. Under the current college English teaching model, students only passively receive the knowledge taught by teachers, lack the ability to think independently, and actively explore the spirit in the learning process. PAD Class shift students' learning from simple and passive "acceptanceoriented" to "thinking and communication-oriented." At the same time, various discussions within, between groups, online, and offline can give every student the opportunity and space to fully demonstrate and exercise. In the teacher's positive feedback and guidance, outstanding students will be better in the future, while students who perform generally will work harder in the future.

Discussions across the class. Student discussion is common in language classes, but this kind of "discussion" actually violates the basic laws of psychology in the learning process: Students lacked a deep understanding of the new content they had just contacted and could not effectively discuss it. The discussion process was often notorious. In addition, "discussion" is often dominated by a small number of students learning to discuss, most students are only passively involved. The "discussion across the class" of PAD class gave students sufficient time to understand what they had learned in the class, reduced their anxiety about new language content, and ensured high quality and efficient discussions. This helps students build confidence in using English to express their ideas and achieve better learning results.

Comprehensive systematic teacher-student interaction. Rich interpersonal interaction is a good way to cultivate the activeness of thinking. In the current teaching model, there is no more opportunities for teachers and students to communicate. The language teaching under the PAD Class model emphasizes student and student, teacher and students interaction. In order to achieve a better classroom interaction effect, teachers must specify the form, subject content, and specific division of work in each classroom interaction, and incorporate questions and answers, group debates, topical speeches, language games, and mock job interviews. Therefore, the purpose is clear, and the various interactions with problems can encourage students to learn from others' perspectives and inspire each other in the exchange, and at the same time, to exercise expression and communication skills. In addition, teachers and students can also establish a resource sharing platform through WeChat Group and QQ Group. This platform can also have the function of online interactive communication and answering doubts.

Improve the learning effect. First of all, students learn through the teacher's lectures, review after class, work in groups, and discuss in groups for four times within a week. The understanding is more thorough, the forgetting rate is greatly reduced, and the memory is deeper. Second, because teachers only refine key points and difficulties, in order to participate in the discussion of the next class, students need to learn the content of micro lessons and textbooks did not speak, find relevant information, and record difficulties, doubts and problems. Peer pressure will make students more motivated, more serious and more creative in their understanding and internalization of their knowledge. Again, each time homework is scored, excellent work is displayed in the class. This will motivate students to take the initiative to externalize their learning outcomes into high-quality homework, so as to fully mobilize students' active learning ability. This kind of procedural assessment system urges students to study in peacetime, and spreads the efforts that should be paid for effective learning throughout the semester. It is no longer necessary to learn only for passing the final examination.

\section{CONCLUSION}

The learning strategy is one of the necessary means to construct a second language learner interlanguage, which received extensive attention from the study of second language acquisition [7]. The effective learning strategies are effectively combined and complemented with the PAD Class teaching modes. They are actively applied in the basic English class at Anshan University in order to maximize students' interest in learning and improve their teaching quality.

PAD Class incorporates the advantages of lecture-style classrooms and discussion-style classrooms, and are in line with the cognitive psychology of individual knowledge acquisition. More importantly, the PAD Class tries to get rid of the predicament of current university classroom teaching from a fundamental level, and forms a classroom model that is more suitable for China's national conditions, and provides a new idea for the teaching reform of higher education in China.

\section{REFERENCES}

[1] Zhang Dejiang. Inspiration Education: Education and Teaching Reform [J]. Higher education in China, 2010(20): $38-40$.

[2] Zhang Dejiang. Analysis on the Problems and Models of Applicationoriented Talent Cultivation [J]. Higher education in China, 2011(18): 24 -26 .

[3] Xu Jianguo. The Application of Second Language Acquisition and Learning Strategies in English Learning [J]. Journal of Southwest Guizhou Nationalities Teachers College, 2007(3).

[4] Bao Jing. The Enlightenment of Second Language Acquisition Environment Theory to College English Teaching [J]. Journal of Anhui University of Technology (Social Science Edition), 2007, 24 (5).

[5] Wang Haoqing. The Application of Second Language Acquisition Theory in Foreign Language Learning [J]. Contemporary manager (Late edition), 2006(2).

[6] Zhang Xuexin. PAD Class: A New Attempt in University Teaching Reform [J]. Fudan Teaching Forum, 2014 (5) .

[7] Yu Qingchen, Xu Ping. The practical connotation of contemporary classroom teaching model reform: A reflective perspective [J]. Educational Research, 2014(01): 15-18. 